\title{
Effect of Prophylactic Anti-emetics on Opioid-induced Nausea and Vomiting: A Retrospective Observational Cohort Study
}

\author{
TOMOKI TAMURA, KEITA KAWAKADO, GO MAKIMOTO, MASAMOTO NAKANISHI and SHOICHI KUYAMA
}

Department of Respiratory Medicine, National Hospital Organization Iwakuni Clinical Center, Iwakuni, Japan

\begin{abstract}
Background: The guidelines on pharmacotherapy for cancer-related pain advocate active measures against the adverse effects of opioids to increase adherence to medication. However, preventative therapy for the management of nausea and vomiting has not been specified. This study aimed to verify the effects of prophylactic antiemetics in preventing opioid-induced nausea and vomiting. Patients and Methods: We conducted a retrospective analysis of cases at our hospital in which oral opioids or patches were initiated for the management of pain due to malignant tumours from January 2017 to September 2019. Results: Strong opioids were initiated for 349 patients; of these, data for 298 patients were analysed. A total of 193 patients were on anti-emetic prophylaxis. We found that the group that did not receive anti-emetic prophylaxis was significantly more likely to be prescribed an additional antiemetic. Conclusion: Prophylactic administration of antiemetics at the time of initiating opioid analgesics may reduce gastrointestinal toxicity.
\end{abstract}

For patients with advanced cancer, opioids are very important drugs for the control of pain. Gastrointestinal toxicities, such as constipation and nausea, are the typical adverse effects of opioids. Controlling these adverse effects is important to improve adherence to medication. Guidelines for pharmacotherapy of cancer pain suggest that aggressive measures should be taken to control the adverse side effects and improve compliance. Prophylactic administration of drugs is recommended for constipation; however,

This article is freely accessible online.

Correspondence to: Tomoki Tamura, MD, Ph.D., Department of Respiratory Medicine, National Hospital Organization Iwakuni Clinical Center, 1-1-1 Atago-machi, Iwakuni-City, Yamaguchi 7408510, Japan. Tel: +81 827341000, Fax: +81 827355600, e-mail: tomoki19830211@gmail.com

Key Words: Anti-emetics, opioids, nausea, emesis. prophylactic administration of anti-emetics has not been recommended because few prospective trials have been conducted so far (1-3). Nausea is said to occur in about $40 \%$ of patients after the initiation of opioid therapy (4), but there are few recommendations on opioid-induced nausea and vomiting (OINV) (5); therefore, preventive measures against nausea are considered important.

We report the findings from a retrospective observational study with the primary objectives of estimating the incidence of nausea and understanding the efficacy of anti-emetic prophylaxis during initiation of opioids for the treatment of cancer pain.

\section{Patients and Methods}

Study design and patient selection. This was a single-centre retrospective observational study conducted to understand the incidence of OINV in Japanese patients with cancer pain who were initiated on strong opioid therapy (morphine, oxycodone, hydromorphone, and fentanyl). The study was approved by the relevant Institutional Review Board (National Hospital Organization Iwakuni Clinical Center Institutional Review Board, Iwakuni, Yamaguchi, Japan) (no. 0175) and was conducted in compliance with the Declaration of Helsinki and Ethical Guidelines for Medical and Health Research Involving Human Subjects. Informed consent was obtained using the opt-out option on our hospital website.

The data of patients who were prescribed strong opioids for cancer pain were extracted from their medical records. Patients were excluded when strong opioids had been initiated before the observation period or when they had received strong opioids at other centres. Patients with difficulty in oral intake were also excluded.

Statistical methods. We evaluated the number of patients who required additional anti-emetic medications among those who received no prophylactic anti-emetic drugs. Cases in which an additional anti-emetic was prescribed within 28 days after the initiation of the strong opioid were defined as receiving an additional prescription. Differences between the groups were assessed using the chi-squared test and Fisher's exact test. The Kaplan-Meier method was used to evaluate the period until the use of anti-emetics. Gray's test was used to evaluate the cumulative incidence of additional use of anti-emetics and death within 1 month from the use of opioids. Age, sex, primary site of cancer, prescribed opioid types and dosage, history of tramadol administration, 


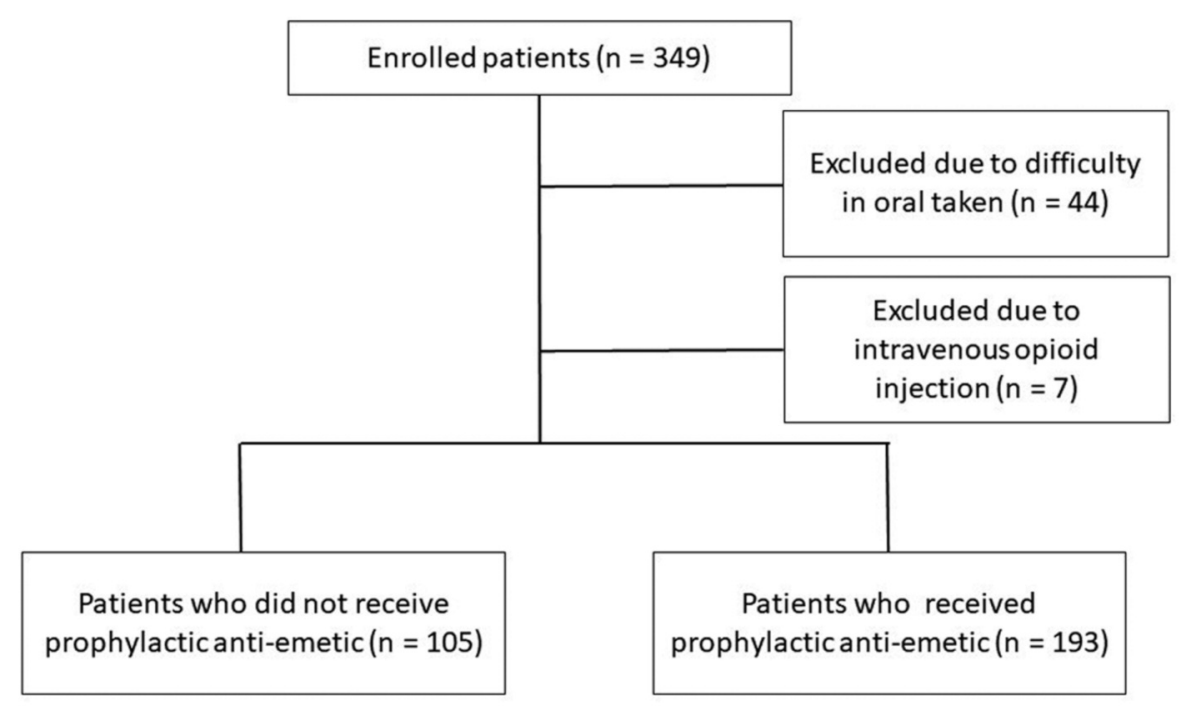

Figure 1. Flow chart showing recruitment of patients in this study.

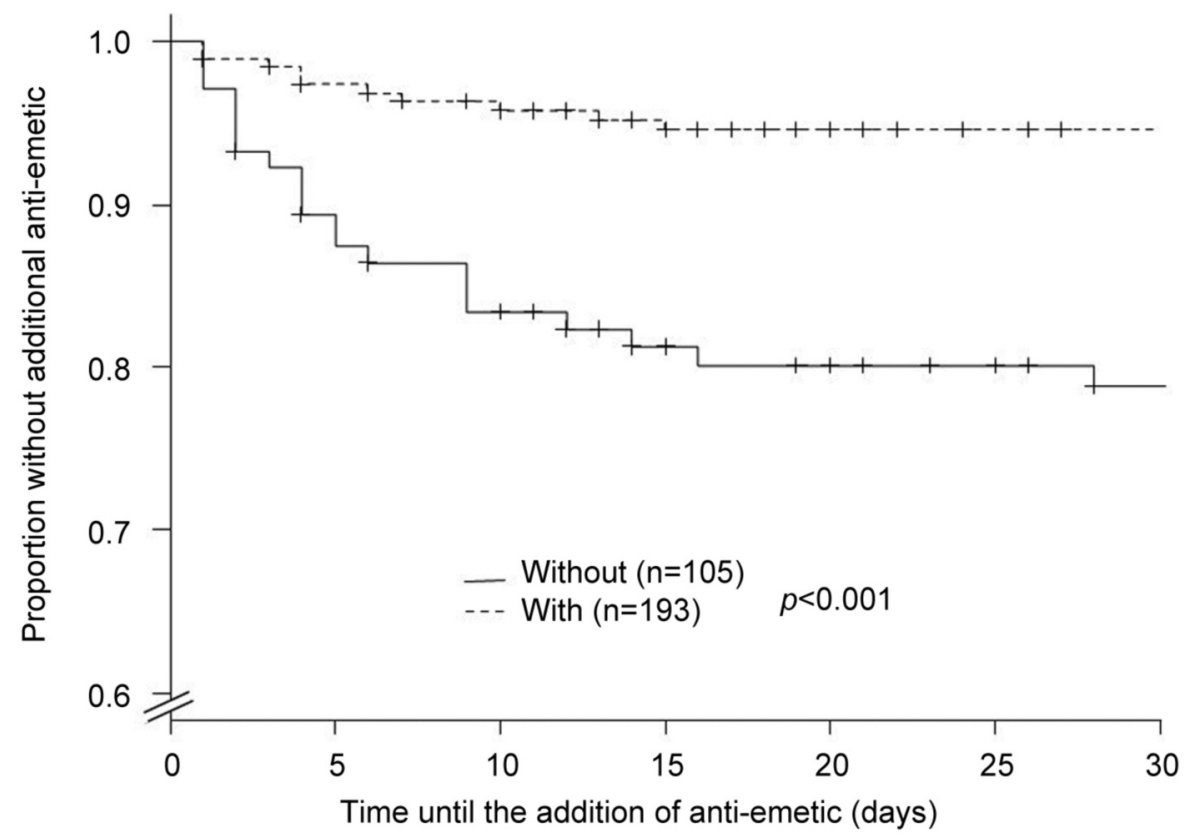

Figure 2. Time to administration of additional anti-emetic medicine. Time-to-event endpoints were analysed using Kaplan-Meier methods and were tested using the log-rank test.

subsequent administration of anticancer drugs, and outpatient opioid introduction were adjusted for in the multivariate analysis. All statistical tests were performed on observed values with a two-sided significance level of 0.05 without multiplicity considerations. All statistical analyses were performed with EZR (Saitama Medical Center, Jichi Medical University, Saitama, Japan), which is a graphical user interface for R (The R Foundation for Statistical Computing, Vienna, Austria).

\section{Results}

Patients. Between January 5, 2017 and September 30, 2019, 349 patients with cancer pain were started on strong opioids. Of the 349 patients, 44 were excluded from this study due to difficulty in oral intake, and a further seven were excluded because they received intravenous opioid 
Table I. Demographic and baseline clinical characteristics of the patients.

\begin{tabular}{|c|c|c|c|}
\hline \multirow[b]{2}{*}{ Variable } & \multicolumn{2}{|c|}{ Prophylactic anti-emetic } & \multirow[b]{2}{*}{$p$-Value } \\
\hline & Without $(\mathrm{n}=105)$ & With $(n=193)$ & \\
\hline \multicolumn{4}{|l|}{ Age, years } \\
\hline Median (range) & $69(37-89)$ & $71(35-94)$ & 0.559 \\
\hline \multicolumn{4}{|l|}{ Gender, n (\%) } \\
\hline Male & $60(57.1)$ & $118(61.1)$ & \multirow[t]{2}{*}{0.537} \\
\hline Female & $45(42.9)$ & $75(38.9)$ & \\
\hline \multicolumn{4}{|l|}{ Opioid type, n (\%) } \\
\hline Morphine & $5(4.8)$ & $30(15.5)$ & \multirow[t]{4}{*}{$<0.001$} \\
\hline Oxycodone & $58(55.2)$ & $129(66.8)$ & \\
\hline Hydromorphone & $8(7.6)$ & $12(6.2)$ & \\
\hline Fentanyl (patch) & $34(32.4)$ & $22(11.4)$ & \\
\hline \multicolumn{4}{|l|}{ Primary tumor, n (\%) } \\
\hline Digestive tract & $31(29.5)$ & $24(12.4)$ & \multirow[t]{2}{*}{$<0.001$} \\
\hline Other & $74(70.5)$ & $169(87.6)$ & \\
\hline \multicolumn{4}{|l|}{$\begin{array}{l}\text { Chemotherapy after } \\
\text { opioid induction, } \mathrm{n}(\%)\end{array}$} \\
\hline Yes & $35(33.3)$ & $77(39.9)$ & \multirow[t]{2}{*}{0.317} \\
\hline No & $70(66.7)$ & $116(60.1)$ & \\
\hline \multicolumn{4}{|l|}{$\begin{array}{l}\text { History of weak opioid } \\
\text { administration, n (\%) }\end{array}$} \\
\hline Yes & $44(41.9)$ & $85(44)$ & \multirow[t]{2}{*}{0.807} \\
\hline No & $61(58.1)$ & $108(56)$ & \\
\hline \multicolumn{4}{|l|}{$\begin{array}{l}\text { Status within } 1 \text { month, } \\
\mathrm{n}(\%)\end{array}$} \\
\hline Alive & $78(74.3)$ & $142(73.6)$ & \multirow[t]{3}{*}{$>0.99$} \\
\hline Dead & $25(23.8)$ & $47(24.4)$ & \\
\hline Unknown & $2(1.9)$ & $4(2.1)$ & \\
\hline \multirow{2}{*}{\multicolumn{4}{|c|}{$\begin{array}{l}\text { Opioid rotation within } \\
1 \text { month, } \mathrm{n}(\%)\end{array}$}} \\
\hline & & & \\
\hline Yes & $78(74.3)$ & $122(63.2)$ & \multirow[t]{3}{*}{0.128} \\
\hline No & $25(23.8)$ & $67(34.7)$ & \\
\hline Unknown & $2(1.9)$ & $4(2.1)$ & \\
\hline \multicolumn{4}{|l|}{$\begin{array}{l}\text { Opioid introduction in } \\
\text { outpatient setting, n (\%) }\end{array}$} \\
\hline Yes & $94(89.5)$ & $151(78.2)$ & \multirow[t]{2}{*}{0.017} \\
\hline No & $11(10.5$ & $42(21.8)$ & \\
\hline $\begin{array}{l}\text { Median dose (morphine } \\
\text { equivalent), } \mathrm{mg}\end{array}$ & $15(7.5-60)$ & $15(10-75)$ & $<0.001$ \\
\hline
\end{tabular}

Fisher's exact test was used to compare the two groups, and $t$-test was used to test the continuous variables. Statistically significant $p$-values are shown in bold.

injection. The data for the remaining 298 patients were retrospectively analysed (Figure 1). The anti-emetics used in our study were prochlorperazine and metoclopramide. The patients' demographic and baseline clinical characteristics are shown in Table I. The patients in the group that received no anti-emetic prophylaxis had significantly advanced gastrointestinal tract carcinoma, used fentanyl more often, had received opioids more often at the Outpatient Department, and were initiated on opioids at lower doses than those in the group that received prophylactic anti-emetic.
Table II. Results of the multivariate analysis for the need of an additional anti-emetic.

\begin{tabular}{lccc}
\hline Variable & OR & $95 \%$ CI & $p$-Value \\
\hline $\begin{array}{l}\text { Age } \\
\quad \text { 70 Years }\end{array}$ & 0.706 & $0.3080-1.620$ & 0.409 \\
$\begin{array}{l}\text { Gender } \\
\quad \text { Male }\end{array}$ & 0.39 & $0.1720-0.886$ & $\mathbf{0 . 0 2 4 6}$ \\
$\begin{array}{l}\text { Primary tumor } \\
\quad \text { Digestive tract }\end{array}$ & 0.59 & $0.1800-1.930$ & 0.384 \\
$\begin{array}{l}\text { Opioid } \\
\quad \text { Fentanyl patch }\end{array}$ & 0.541 & $0.1770-1.660$ & 0.283 \\
$\quad \begin{array}{l}\text { Morphine } \\
\text { Opioid introduction in }\end{array}$ & 0.65 & $0.1430-2.950$ & 0.576 \\
$\quad \begin{array}{l}\text { outpatient setting } \\
\quad \text { Yes }\end{array}$ & 0.367 & $0.0784-1.720$ & 0.203 \\
$\begin{array}{l}\text { History of weak opioid } \\
\text { administration } \\
\quad \text { Yes }\end{array}$ & & & \\
$\begin{array}{l}\text { Prophylactic anti-emetic } \\
\quad \text { Yes }\end{array}$ & 2.33 & $0.9370-5.810$ & 0.0686 \\
$\begin{array}{l}\text { History of chemotherapy } \\
\text { after opioid induction } \\
\quad \text { Yes }\end{array}$ & 0.212 & $0.0857-0.524$ & $\mathbf{0 . 0 0 0 8}$ \\
$\begin{array}{l}\text { Opioid dose } \\
\quad>15 \text { mg }\end{array}$ & 1.06 & $0.4460-2.520$ & 0.894 \\
\hline
\end{tabular}

CI: Confidence interval; OR: odds ratio. Logistic regression analysis was used for multivariate analysis. Statistically significant $p$-values are shown in bold.

Incidence of additional anti-emetic medications. The cumulative incidence of the need for additional anti-emetics within 4 weeks was $20.0 \%$ (21 out of 105 patients) in the group that received no anti-emetic prophylaxis, and 5.2\% (10 out of 193 patients) in the group that received prophylactic anti-emetics (odds ratio $=0.220,95 \%$ confidence intervaI $=0.088-0.513, p<0.001)$. The duration from initiation of opioids to the need for additional anti-emetic treatment was shorter in the non-prophylactic group than that in the prophylactic group $(p<0.001$; Figure 2$)$. Since it is difficult to evaluate whether additional anti-emetics were prescribed to patients who died early, the same test was performed while excluding patients who died within 2 weeks of the start of opioids and patients who died within 4 weeks of the start of opioids. The results showed that anti-emetics were added significantly earlier in the non-prophylactic group than in the prophylactic group, as observed in the overall cohort analysis (both $p<0.001$ ). Since it cannot be ruled out that the cumulative incidence of additional anti-emetics and premature mortality may be competing factors, Gray's test was performed. The results also showed that prophylactic anti-emetic use significantly suppressed the addition of antiemetics and had no effect on death $(p<0.001$ and $p=0.902$, respectively; Figure 3). Multivariate analysis showed that an 
A

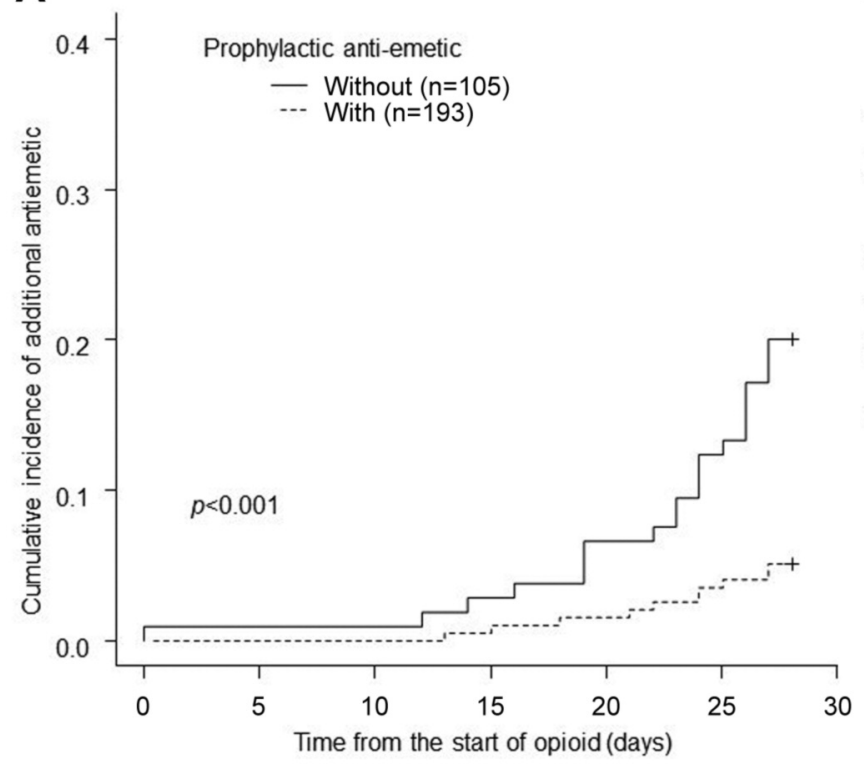

B

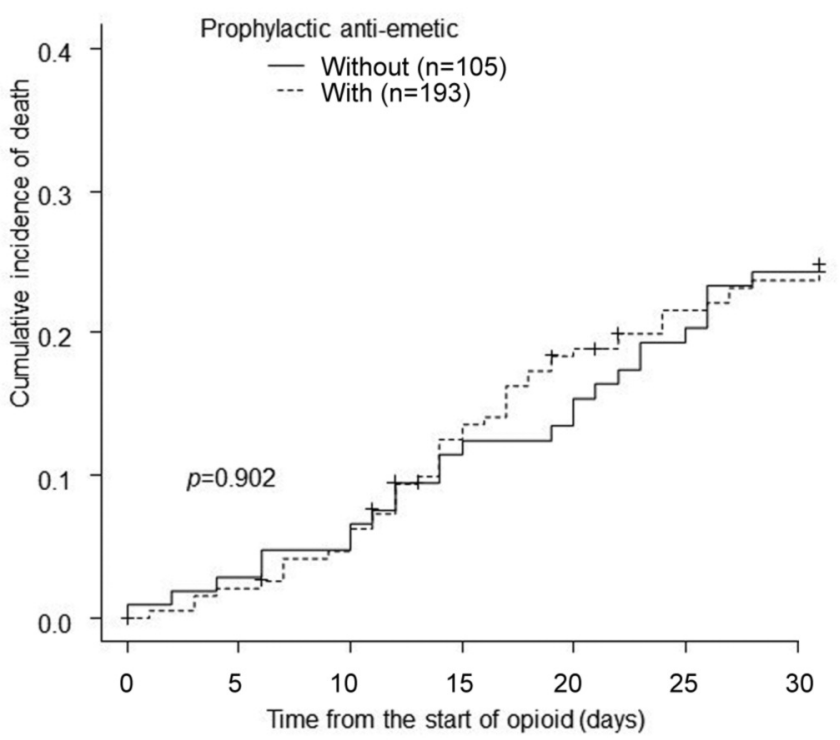

Figure 3. Cumulative incidence of additional use of anti-emetic $(A)$ and death within 1 month $(B)$ of opioid use according to treatment with and without prophylactic anti-emetic. The cumulative incidence of additional use of anti-emetics and death within 1 month was analysed using Gray's test.

additional anti-emetic was more often prescribed for females in the group without prophylactic anti-emetic, and for the patients who were switched from tramadol to strong opioids. These differences were found to be significant (Table II).

\section{Discussion}

Several studies have reported on prophylactic anti-emetic use for OINV. One study reported that $82 \%$ of Japanese physicians prescribed prophylactic anti-emetics at the initiation of opioid therapy, despite the lack of evidence regarding their prophylactic benefit (6). Another study reported that $45 \%$ of physicians in Italy reported using prophylactic anti-emetic drugs for OINV (7), which is much lower than the reported use in Japan. In our study, a prophylactic anti-emetic was administered to prevent OINV in $64.8 \%$ of the patients receiving strong opioids, which is less than that stated in a previous report in Japan (6). The lower rate of prophylactic anti-emetic use recorded in this study may be because this was a single-centre retrospective study.

In a previous single-centre study of 83 patients in Japan, prophylactic treatment with anti-emetics was reported to reduce the incidence of OINV (8). Several other retrospective studies reported that premedication with dopamine D2 blockers was not effective for preventing OINV (9-11). In our study, prophylactic anti-emetic use significantly reduced the need for additional anti-emetics (odds ratio $0.220,95 \%$ confidence intervaI $=0.0883-0.513, p=0.0001$ ). However, a randomized, placebo-controlled, double-blind trial to evaluate the efficacy and safety of prophylactic treatment with prochlorperazine for preventing OINV reported no prophylactic benefit of prochlorperazine, and the routine use of prochlorperazine as a prophylactic anti-emetic at the initiation of opioid treatment was not recommended (12). In addition to prochlorperazine, metoclopramide and olanzapine are used as treatment options for OINV but they are mainly dopamine D2 inhibitors. At the Emergency Department, ondansetron is often used to prevent OINV but a prospective observational study reported that ondansetron did not actually appear to be effective in preventing OINV (13). Hence, for the prevention of OINV, appropriate drugs need to be identified and evaluated in a prospective study.

Our study had several limitations. Firstly, no outcomes have been established for use in clinical trials to assess the efficacy of any medication to prevent OINV. We evaluated outcomes regarding the need for an additional anti-emetic in this study but the validity of our method cannot be confirmed. Moreover, it would have been helpful to evaluate whether the patients developed nausea, but because our study was retrospective, using data from the medical records, it was not possible to make a detailed evaluation of the symptoms of nausea. Furthermore, we did not evaluate whether nausea was actually the reason for opioid switching.

Gastrointestinal tract tumours were more common in the group that did not receive prophylactic administration of anti-emetics, and there was also a difference in the type of opioid used (Table I). Patients with primary gastrointestinal 
A

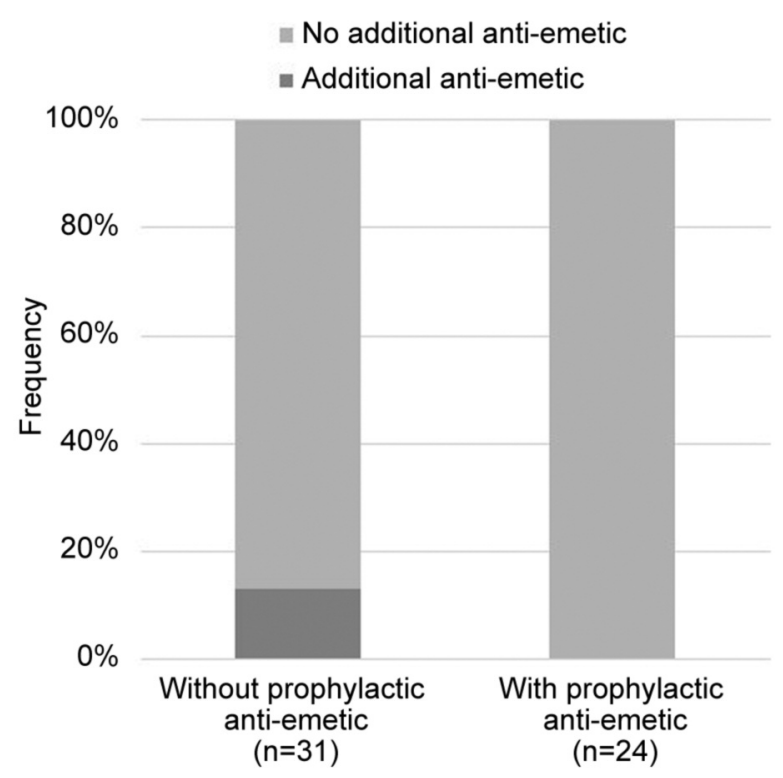

B

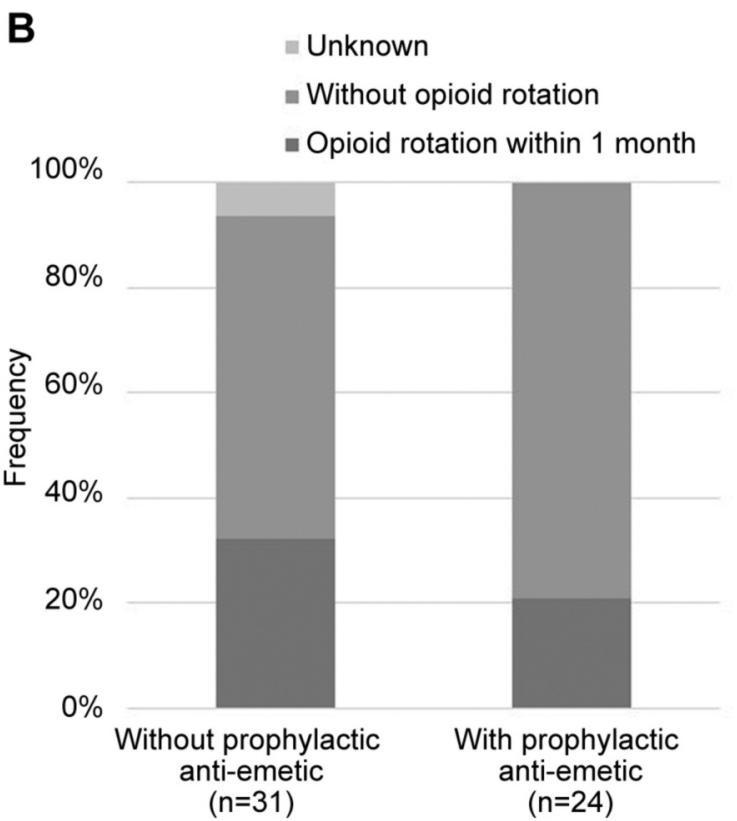

Figure 4. Incidence of the need for additional anti-emetics (A) and short-term opioid rotation (B) in patients with gastrointestinal tumour.

tumours were less likely to be prescribed prophylactic antiemetics and more likely to receive fentanyl. Although no significant difference was found in the multivariate analysis, it cannot be denied that the difference in primary lesions may have led to the need for additional prescription of antiemetics. In addition, patients who were introduced to opioids as outpatients were less likely to receive prophylactic antiemetics, and the non-preventative group tended to be prescribed lower doses of opioids at the time of introduction. We think it is unlikely that this caused the additional prescription. In patients with gastrointestinal tumour, there was no significant difference between the groups with and without prophylactic anti-emetic regarding the use of additional anti-emetics and short-term opioid rotation ( $p=0.123$ and 0.364 , respectively; Figure 4).

On multivariate analysis, the use of prophylactic antiemetic agents, and sex were independent factors that influenced the need for additional anti-emetic drugs (Table I). There were many males in the prophylactic anti-emetic group but there was no significant difference in sex between the two groups. Previous studies have also shown that female sex is a risk factor for OINV, and it cannot be ruled out that this study may have influenced the results $(11,14)$. Interestingly, although there was no significant statistical difference, patients who were switched from tramadol were more likely to be prescribed additional anti-emetics. A separate study reported that the adverse effects of strong opioids were more pronounced in patients with a history of tramadol treatment (15). Similar results were obtained in our study. Despite limited research results, prophylactic administration of anti-emetic drugs seems to be effective in preventing OINV.

The results of this study demonstrate that prophylactic administration of anti-emetics at the initiation of opioid analgesics might reduce OINV. Routine use of prophylactic anti-emetics at the initiation of opioid treatment is not recommended, but some patients might benefit from prophylactic anti-emetics. Further research is necessary to select suitable anti-emetics for prophylactic administration to prevent OINV.

\section{Conflicts of Interest}

The Authors declare no conflicts of interest in regard to this study.

\section{Authors' Contributions}

Tamura $\mathrm{T}$ wrote the article, Tamura T, Kawakado K, Makimoto G, Nakanishi M contributed to all aspects of the study's design, Kuyama S supervised the article and prepared the final version of the article. All listed Authors contributed to the arguments of the article and read and approved the final submission.

\section{Acknowledgements}

The Authors would like to thank Editage (www.editage.com) for English-language editing. This research did not receive any specific grant from funding agencies in the public, commercial, or not-forprofit sectors. 


\section{References}

1 Laugsand EA, Kaasa S and Klepstad P: Management of opioidinduced nausea and vomiting in cancer patients: systematic review and evidence-based recommendations. Palliat Med 25(5): 442-453, 2011. PMID: 21708851. DOI: 10.1177/02692163 11404273

2 Walsh D, Davis M, Ripamonti C, Bruera E, Davies A and Molassiotis A: 2016 Updated MASCC/ESMO consensus recommendations: Management of nausea and vomiting in advanced cancer. Support Care Cancer 25(1): 333-340, 2017. PMID: 27534961. DOI: 10.1007/s00520-016-3371-3

3 Yamaguchi T, Shima Y, Morita T, Hosoya M, Matoba M and Japanese Society of Palliative Medicine.: Clinical guideline for pharmacological management of cancer pain: the Japanese Society of Palliative Medicine recommendations. Jpn J Clin Oncol 43(9): 896-909, 2013. PMID: 23885114. DOI: 10.1093/ jjco/hyt099

4 Aparasu R, McCoy RA, Weber C, Mair D and Parasuraman TV: Opioid-induced emesis among hospitalized nonsurgical patients: effect on pain and quality of life. J Pain Symptom Manage 18(4): 280-288, 1999. PMID: 10534968. DOI: 10.1016/s08853924(99)00085-8

5 Sande TA, Laird BJA and Fallon MT: The management of opioid-induced nausea and vomiting in patients with cancer: A systematic review. J Palliat Med 22(1): 90-97, 2019. PMID: 30239277. DOI: 10.1089/jpm.2018.0260

6 Tsukuura H, Ando Y, Gyawali B, Matsumoto M, Sugishita M, Honda K, Urakawa H, Maeda O and Hasegawa Y: Prophylactic use of antiemetics for prevention of opioid-induced nausea and vomiting: A questionnaire survey among japanese physicians. J Palliat Med 18(11): 977-980, 2015. PMID: 26509390. DOI: 10.1089/jpm.2015.0203

7 Giusti R, Mazzotta M, Filetti M, Daniele G, Tsukuura H, Ficorella C, Porzio G, Marchetti P and Verna L: Prophylactic use of antiemetics for prevention of opioid-induced nausea and vomiting: a survey about Italian physicians' practice. Support Care Cancer 27(9): 3531-3535, 2019. PMID: 30684048. DOI: 10.1007/s00520-019-4663-1

8 Ishihara M, Iihara H, Okayasu S, Yasuda K, Matsuura K, Suzui M and Itoh Y: Pharmaceutical interventions facilitate premedication and prevent opioid-induced constipation and emesis in cancer patients. Support Care Cancer 18(12): 1531-1538, 2010. PMID: 19921282. DOI: 10.1007/s00520-009-0775-3
9 Ishihara M, Ikesue H, Matsunaga H, Suemaru K, Kitaichi K, Suetsugu K, Oishi R, Sendo T, Araki H, Itoh Y and Japanese Study Group for the Relief of Opioid-induced Gastrointestinal Dysfunction: A multi-institutional study analyzing effect of prophylactic medication for prevention of opioid-induced gastrointestinal dysfunction. Clin J Pain 28(5): 373-381, 2012. PMID: 22156893. DOI: 10.1097/AJP.0b013e318237d626

10 Okamoto Y, Tsuneto S, Tsugane M, Takagi T and Uejima E: A retrospective chart review of opioid-induced nausea and somnolence on commencement for cancer pain treatment. J Opioid Manag 6(6): 431-434, 2010. PMID: 21269004. DOI: 10.5055/jom.2010.0041

11 Kanbayashi Y and Hosokawa T: Predictive factors for nausea or vomiting in patients with cancer who receive oral oxycodone for the first time: is prophylactic medication for prevention of opioid-induced nausea or vomiting necessary? J Palliat Med 17(6): 683-687, 2014. PMID: 24702605. DOI: 10.1089/jpm. 2013.0613

12 Tsukuura H, Miyazaki M, Morita T, Sugishita M, Kato H, Murasaki Y, Gyawali B, Kubo Y, Ando M, Kondo M, Yamada $\mathrm{K}$, Hasegawa Y and Ando Y: Efficacy of prophylactic treatment for oxycodone-induced nausea and vomiting among patients with cancer pain (POINT): A randomized, placebo-controlled, double-blind trial. Oncologist 23(3): 367-374, 2018. PMID: 29038236. DOI: 10.1634/theoncologist.2017-0225

13 Culver MA, Richards EC, Jarrell DH and Edwards CJ: Use of prophylactic ondansetron with intravenous opioids in emergency department patients: a prospective observational pilot study. J Emerg Med 53(5): 629-634, 2017. PMID: 28987314. DOI: 10.1016/j.jemermed.2017.06.040

14 Cepeda MS, Farrar JT, Baumgarten M, Boston R, Carr DB and Strom BL: Side effects of opioids during short-term administration: effect of age, gender, and race. Clin Pharmacol Ther 74(2): 102-112, 2003. PMID: 12891220. DOI: $10.1016 /$ S0009-9236(03)00152-8

15 Corli O, Santucci C, Corsi N, Radrezza S, Galli F and Bosetti C: The burden of opioid adverse events and the influence on cancer patients' symptomatology. J Pain Symptom Manage 57(5): 899-908.e6, 2019. PMID: 30776537. DOI: 10.1016/j. jpainsymman.2019.02.009

Received January 14, 2021

Revised February 8, 2021

Accepted February 9, 2021 